\title{
Audiology
}

\section{Restoration of auditory network after cochlear implant in prelingual deafness: a P300 study using LORETA}

\author{
Ripristino del network uditivo dopo impianto cocleare in soggetti affetti da sordità \\ prelinguale: studio del potenziale P300 attraverso l'utilizzo di LORETA
}

\author{
Sara Ghiselli ${ }^{\star}$, Flavia Gheller ${ }^{2 *}$, Patrizia Trevisi ${ }^{2}$, Emanuele Favaro ${ }^{3}$, Alessandro Martini², Mario Ermani ${ }^{3}$ \\ ${ }^{1}$ Institute for Maternal and Child Health- IRCSS Burlo Garofolo, Trieste, Italy; ${ }^{2}$ ENT Clinic, Department of Neuroscience, Padova \\ University Hospital, Padova, Italy; ${ }^{3}$ Neurological Clinic, Department of Neuroscience, Padova University Hospital, Padova, Italy \\ * S. Ghiselli and F. Gheller contributed equally to this work.
}

\begin{abstract}
SUMMARY
The concept of auditory restoration after cochlear implant (CI) in prelingual deafness is well described by a synaptic network model, whose development depends on sensory experience. The aim of this work was to study the associative networks activated by the CI in a population of prelingually deaf patients. In particular, the impact of age at time of first CI fitting and duration of CI use was evaluated. Twenty patients were tested and divided into three groups: early implanted and lengthy CI use (group A); late implanted and lengthy CI use (group B); late implanted and short CI use (group C). Each patient group was compared with a normal hearing age matched control group. All subjects underwent to auditory event-related potentials (ERPs) registration. ERP latencies and their cortical sources were investigated. Cortical source analysis was performed using LORETA (Low Resolution Electromagnetic Tomography) software. P300 latencies were significantly longer in patients than in controls. The amount of cortical activation was found to be significantly directly correlated with duration of implant use and significantly correlated inversely with age at implant. When comparing patients and controls, comparable cortical activation was only found in A patient group, and to a lesser extent in group B, while significantly lower activation was found in patient group $\mathrm{C}$ in the frontal and cingulate areas. CI adds a sensory modality in deafness patients, i.e. the auditory one. This involves areas implicated in sensory and cognitive functions, and needs some time to form. The duration of CI use is crucial: our results demonstrate the importance of long term use of the device in addition to an early time of implant.
\end{abstract}

KEY WORDS: cochlear implant, LORETA, cortical activation, ERPs, hearing loss

\section{RIASSUNTO}

La letteratura è concorde su come, in pazienti affetti da ipoacusia perlinguale, il ripristino uditivo secondario ad impianto cocleare (IC) sia paragonabile ad un modello di network sinaptico attivato dall'esperienza uditiva. Scopo di questo studio è la valutazione di quali networks cerebrali si attivino secondariamente ad impianto cocleare in una popolazione di pazienti ipoacusici preverbali. In particolare, verrà valutato come alcuni fattori, quali l'età all'attivazione ed il tempo di utilizzo dell'IC, incidano nel ripristino della percezione uditiva. Sono stati valutati 20 pazienti suddivisi in 3 gruppi: impianto precoce e lungo utilizzo dell'IC (gruppo A); impianto tardivo e lungo utilizzo dell'IC (gruppo B); impianto tardivo e breve utilizzo dell'IC (gruppo C). Tutti i pazienti sono stati comparati con soggetti normoacusici di pari età. La valutazione si è avvalsa dell'utilizzo di potenziali uditivi evento correlati (ERPS); in particolare sono state valutate le latenze dei potenziali (N200 e P300) e le sorgenti corticali tramite utilizzo del software LORETA. Le latenze del potenziale P300 sono risultate aumentate nei pazienti rispetto ai controlli. Dall'analisi delle sorgenti corticali è stato riscontrato che l'attivazione corticale nei pazienti è direttamente correlata con il tempo di utilizzo del dispositivo ed inversamente correlata con l'età d'impianto. Dal confronto dei pazienti suddivisi in gruppi rispetto ai controlli, un'attivazione corticale similare nelle aree frontali e cingolata, è stata riscontrata solo nel gruppo A, in minor misura nel gruppo B e notevolmente ridotta nel gruppo $C$. In conclusione, l'IC apporta una reale
Received: August 17, 2018

Accepted: November 24, 2018

Published on line: September 30, 2019

\section{Correspondence}

Sara Ghiselli

ENT and Audiology Department, Institute for Maternal and Child Health, IRCSS Burlo Garofolo, via dell'Istria65, 34137 Trieste, Italy

Tel. +39040 3785218

E-mail: sara.ghiselli@burlo.trieste.it

Funding

None.

Conflict of interest

The Authors declare no conflict of interest.

How to cite this article: Ghiselli S, Gheller F, Trevisi P, et al. Restoration of auditory network after cochlear implant in prelingual deafness: a P300 study using LORETA. Acta Otorhinolaryngol Ital 2020;40:64-71. https://doi. org/10.14639/0392-100X-2316

(c) Società Italiana di Otorinolaringoiatria e Chirurgia Cervico-Facciale

\section{(c) (1) $(9$}

This is an open access article distributed in accordance with the CC-BY-NC-ND (Creative Commons Attribution-NonCommercial-NoDerivatives 4.0 International) license. The article can be used by giving appropriate credit and mentioning the license, but only for non-commercial purposes and only in the original version. For further information: https:// creativecommons.org/licenses/by-nc-nd/4.0/deed.en 
attivazione delle aree cerebrali implicate nelle funzioni sensoriali e cognitive ma, per ottenere risposte simili ai normoudenti, necessita di un tempo di utilizzo prolungato. I risultati di questo studio evidenziano come la precocità di impianto ed il tempo di utilizzo del dispositivo siano fattori cruciali per l'attivazione dei newtorks cerebrali nei soggetti ipoacusici preverbali.

PAROLE CHIAVE: impianto cocleare, LORETA, attivazione corticale, ERPs, ipoacusia

\section{Introduction}

Cochlear implant $(\mathrm{CI})$ is a medical device designed to restore hearing perception in patients with severe to profound hearing impairment who fail to benefit adequately from hearing aids ${ }^{1}$. Many studies agree that providing CI early in cases of congenital hearing loss helps patients to develop auditory skills that are comparable with those of their normally-hearing peers ${ }^{2,3}$. Reported outcomes may differ according to the different aetiologies and degrees of hearing loss, prompting changes in neural organisation secondary to auditory deprivation ${ }^{4,5}$. It is well known that there is a sensitive period (before 3.5 years of age) for inserting the $\mathrm{CI}$ in order to achieve normal central auditory development and improve language skills ${ }^{6-8}$, whereas subjects fitted with CI after this period have worse outcomes ${ }^{9}$.

The problem of sensory restoration in early deafness is well explained in a review by Kral et al. ${ }^{10}$ on the basis of the connectome concept. The authors said that sensory loss can be seen as a disease involving the connectome, which is a synaptic network whose development depends on sensory experience.

The proper functioning of auditory processing needs integration of many types of information: neuronal activity relies on both bottom-up and top-down integration ${ }^{11}$. Hearing loss causes changes in connectivity "within the auditory system, between sensory systems, and between the auditory system and centres serving higher-order neurocognitive functions" ${ }^{10}$. Auditory input presumably activates a cortical network of higher-order functions, and sensory restoration with CI can improve the connectivity in this network ${ }^{10}$. This system can be studied using neurophysiological and neuroimaging techniques.

Functional MRI (fMRI) is a powerful neuroimaging method for assessing spatial activations, but is only partially feasible in patients with CI due to factors that include a sizable artefact and the risk of the device being displaced due to potential movement within a magnetic field greater than 1.5 Tesla ${ }^{12,13}$. Other approaches have been used to identify cortical auditory activation in patients fitted with CI, such as NIRS or PET. These procedures, however, have good spatial but poor temporal resolution.

Electroencephalography (EEG), on the other hand, allows estimation of cortical areas of activation even at sub-second timescales. Despite poor spatial resolution, EEG has an excellent time resolution. It is completely non-invasive, easy to use, inexpensive and perfectly compatible with cochlear implantation.

In particular, the event-related potential (ERP) P300 may be an excellent measure of attention and memory operations ${ }^{14}$. The P300 wave is one of the late auditory eventrelated potentials, and is an objective measurement of cognitive processes induced by auditory stimulation. It reflects the cortical processes involved in stimulus evaluation and categorisation, memory operations and decision-making skills. Very few studies have investigated P300 in prelingually deaf CI recipients. Jordan et al. ${ }^{15}$ measured P300 in a very small population of three prelingually and two postlingually deaf CI recipients. Henkin et al. ${ }^{16}$ enrolled 10 prelingually deaf children fitted with CI (9 to 14 years old) and investigated how an increase of acoustic-phonetic difficulty affected the $\mathrm{P} 300$ potential. The interaction between task difficulty and prelingual deafness could not be investigated, however, because there was no control group. Reis et al. ${ }^{17}$ studied P300 latency and amplitude in 29 patients with prelingual, severe-to-profound sensorineural hearing loss (without $\mathrm{CI}$ ), and found significant differences in latency and amplitude that were related to age and severity of hearing loss, respectively. The study had no control group and the ERP was only delivered in $\mathrm{Cz}$ electrode. Beynon et al. ${ }^{18}$ examined 10 congenitally deaf children fitted with CI when 5 or more years old, who had been using the device for at least 2 years. This study included a control group of normal-hearing subjects with longer P300 latencies (mean $500 \mathrm{msec}$ ) than those reported in the literature (mean 300 msec) ${ }^{19}$. A previous study ${ }^{20}$ compared N100, N200 and P300 latencies in 15 prelingually deaf CI recipients with those of nine normal-hearing controls. We found all latencies were significantly longer in the patient group than in controls (whose values were consistent with the literature). Henkin et al. ${ }^{21}$ studied the P3 component elicited by nonspeech and speech oddball discrimination tasks in four prelingual patients with CI. They used LORETA (LowResolution Electromagnetic Tomography) ${ }^{22}$, a noninvasive functional neuroimaging method based on scalp-recorded EEG, to estimate cortical sources of EEG activity. They found differences between patients and controls, and also between right and left $\mathrm{CI}$ recipients.

To date, the age at implant, its period of use and their interaction have not been fully investigated. The aim of our study was to investigate these issues: this was done through 
assessment of the cortical sources of P300, using LORETA software, in prelingually deaf CI recipients compared with age-matched normal-hearing controls.

\section{Materials and methods}

\section{Inclusion criteria}

The inclusion criteria for the study group were: a) congenital non-progressive severe-to-profound bilateral sensorineural hearing loss; b) use of CI; c) no associated disabilities or diseases.

\section{Patients}

We enrolled 20 subjects in the control group ( 3 males and 17 females) and 20 subjects (attending the ENT Clinic at Padua University Hospital) in the study group (11 males and 9 females). The mean age of the control group was $29.05 \pm 16.4$ (range:10.1-58.4), while for the patient group it was $31.10 \pm 18.4$ (range:10.5-62.4). The age difference was not statistically significant $(\mathrm{p}=0.3)$.

Age at the time of first fitting CI (CI Age) and period of $\mathrm{CI}$ use are considered very important parameters. Patients were then divided into groups according to the age at time of CI first fitting, before or after the age of 3 years, (hereinafter referred to as early or late CI age, respectively), and according to the duration of CI use at the time of ERPs recording, less or more than 1 year, (hereinafter named as long or short CI use, respectively).

The three groups are therefore identified as follows: 1) group A, 8 early CI age and long CI use subjects; 2) group B, 5 late $\mathrm{CI}$ age and long $\mathrm{CI}$ use subjects; 3 ) group $\mathrm{C}, 7$ late $\mathrm{CI}$ age and short CI use subjects. No early CI age and short CI use patients were included in the study because they were too young to perform the task required. The characteristics of the patient groups (sex, age at time of the test, aetiology of hearing loss, age at time of first CI fitting, side of CI, CI brand and study subgroup) are summarised in Table I. Each patient group was compared with a control group matched for mean age and sample size. Controls were normal hearing subjects (thresholds lower than $30 \mathrm{~dB}$ at all frequencies). The characteristics of the three groups (age for both control and patient groups, plus age at time of CI and duration of CI use for the patient groups) are summarised in Table II.

The auditory benefit of the CI was assessed in terms of the free-field aided threshold by measuring the pure-tone average (PTA), which is expressed in decibels of hearing level (dB HL) and corresponds to the average air-tonal threshold at the frequencies of 500, 1000 and $2000 \mathrm{~Hz}$. The mean PTA was 32.76 dB HL (range 25-41.2 dB HL) for group A,

Table I. Clinical characteristics of the patient group. CX26 = connexin 26 .

\begin{tabular}{|c|c|c|c|c|c|c|}
\hline Sex & $\begin{array}{l}\text { Age at time of test } \\
\text { (years) }\end{array}$ & Etiology & $\begin{array}{l}\text { Age at first time of Cl fitting } \\
\text { (years) }\end{array}$ & Side of $\mathrm{Cl}$ & Cl Brand & Patient group \\
\hline $\mathrm{F}$ & 14.82 & CX26 & 1.55 & $\mathrm{R}$ & Advanced Bionics & A \\
\hline $\mathrm{F}$ & 13.29 & CX26 & 2.60 & $\mathrm{R}$ & Advanced Bionics & $A$ \\
\hline M & 11.30 & Unknown & 2.53 & $\mathrm{R}$ & Cochlear $^{\circledR}$ & A \\
\hline$M$ & 12.41 & cX26 & 1.63 & $\mathrm{R}$ & Advanced Bionics & $A$ \\
\hline$M$ & 10.50 & Unknown & 3.02 & $\mathrm{R}$ & Cochlear $^{\circledR}$ & $A$ \\
\hline $\mathrm{F}$ & 20.00 & CX26 & 2.45 & $L$ & Medel & A \\
\hline M & 58.70 & Unknown & 57.36 & L & Advanced Bionics & B \\
\hline $\mathrm{F}$ & 25.83 & Unknown & 22.52 & $L$ & Cochlear $^{\circledR}$ & B \\
\hline M & 41.99 & Rubella & 39.86 & $\mathrm{R}$ & Advanced Bionics & B \\
\hline M & 17.92 & CX26 & 17.21 & L & Advanced Bionics & C \\
\hline $\mathrm{F}$ & 42.38 & Unknown & 41.31 & $L$ & Advanced Bionics & C \\
\hline M & 57.69 & Unknown & 57.36 & $L$ & Advanced Bionics & C \\
\hline $\mathrm{F}$ & 62.41 & Unknown & 61,87 & $\mathrm{R}$ & Cochlear $^{\circledR}$ & C \\
\hline M & 46.92 & Rubella & 46.73 & $L$ & Medel & C \\
\hline $\mathrm{F}$ & 50.80 & Familial & 50.61 & $\mathrm{R}$ & Advanced Bionics & C \\
\hline
\end{tabular}


Table II. Characteristics of the three groups (patients and age-matched controls). Ages (in years) are expressed as mean \pm SD and range. Cl Age means the age at first time of $\mathrm{Cl}$ fitting (in years).

\begin{tabular}{|c|c|c|c|c|}
\hline Clinical & & Patients & Controls & T test ( $p$ value) \\
\hline \multirow[t]{4}{*}{ A } & $\mathrm{N}$ & 8 & 8 & \\
\hline & Age & $\begin{array}{r}13.68 \pm 3.30 \\
(10.50-20.00)\end{array}$ & $\begin{array}{c}13.83 \pm 4.77 \\
(10.08-23.41)\end{array}$ & 0.82 \\
\hline & Cl Age & $\begin{array}{c}2.20 \pm 0.56 \\
(1.51-3.02)\end{array}$ & & \\
\hline & Cl use & $\begin{array}{c}11.48 \pm 3.52 \\
(7.48-17.55)\end{array}$ & & \\
\hline \multirow[t]{4}{*}{ B } & $\mathrm{N}$ & 5 & 5 & \\
\hline & Age & $\begin{array}{c}39.07 \pm 15.38 \\
21.50-58.70\end{array}$ & $\begin{array}{c}39.08 \pm 13.64 \\
(22.48-58.39)\end{array}$ & 0.98 \\
\hline & Cl Age & $\begin{array}{c}35.89 \pm 16.36 \\
(16.8-42.9)\end{array}$ & & \\
\hline & $\mathrm{Cl}$ use & $\begin{array}{c}3.17 \pm 1.44 \\
(1.33-4.73)\end{array}$ & & \\
\hline \multirow[t]{4}{*}{ C } & $\mathrm{N}$ & 7 & 7 & \\
\hline & Age & $\begin{array}{c}45.33 \pm 14.58 \\
(17.92-62.41)\end{array}$ & $\begin{array}{r}39.27 \pm 13.61 \\
(17.69-58.39)\end{array}$ & 0.47 \\
\hline & Cl Age & $\begin{array}{c}42.01 \pm 13.83 \\
(17.21-57.36)\end{array}$ & & \\
\hline & Cl use & $\begin{array}{c}0.47 \pm 0.35 \\
(0.2-1)\end{array}$ & & \\
\hline
\end{tabular}

33.75 dB HL (range 22.5-41.25 dB HL) for group B, and 45.17 dB HL (range 31.25-61.25 dB HL) for group C.

\section{P300 recording}

EEG recordings were obtained with 19 electrodes positioned according to the International 10-20 System (Fp1, F3, C3, P3, O1, F7, T3, T5, Fz, Cz, Pz, Fp2, F4, C4, P4, O2, F8, T4 and T6) with a linked ears reference. The sampling rate was $2048 \mathrm{~Hz}$. A time window of $700 \mathrm{~ms}$ was considered (70 ms pre- and $630 \mathrm{~ms}$ post-stimulus). An amplitude window $( \pm 70 \mu \mathrm{V})$ was used for artifact rejection.

The impedance measured for each electrode was lower than $5 \mathrm{kOhm}$.

The active oddball paradigm was used. It consisted of a sequence of target and standard stimuli (1/7 proportion, 60 target stimuli), randomly presented to the subjects. The stimuli were audio tones on different frequencies, with a comfortable intensity level for all patients $(1000 \mathrm{~Hz}$ for the standard, and $2000 \mathrm{~Hz}$ for the target; duration $100 \mathrm{msec}$ for both; ISI = 1020-1100; intensity $=90 \mathrm{~dB}$ ). All subjects were asked to take count of the number of target stimuli administered.

LORETA is a Laplacian-weighted minimum norm algorithm belonging to a family of linear inverse solution procedures ${ }^{23}$. It is used to estimate cortical sources of scalp potentials ${ }^{21,24}$. Estimated electrical sources are obtained considering a brain model based on the Talairach probability brain atlas, digitised at the Brain Imaging Center of the Montreal Neurological Institute ${ }^{25}$. The model includes 6239 voxels ( $5 \times 5 \times 5 \mathrm{~mm}$ resolution). Notably, LORETA is a reference-free method of EEG analysis.

\section{Types of analysis}

We performed two analyses: a simple study of N200 and P300 latencies and a LORETA cortical source analysis, including a linear regression analysis with duration of CI use and age of CI surgery as covariates.

\section{Latency analysis}

As in the literature and clinical practice, according to which $\mathrm{Cz}$ provides the best evoked response, we always considered $\mathrm{Cz}$ for this analysis. P300 latencies were identified at the maximum wave amplitude of the third positive peak point. The identification of P300 peak latency was performed through visual assessment of the target stimuli traces ${ }^{26}$. In any case, the maximum positive deflection designated as P300 was calculated automatically by the software for P300 acquisition, thus allowing for validation of the latency values determined by visual analysis of the traces.

\section{Cortical source analysis}

First, the difference between the averaged rare response 
and the frequent averaged response was calculated for the 19 channels, and for each patient.

This new function ("rare stimuli response minus frequent stimuli response", which may be considered as the pure target stimuli effect) was collapsed into 63 bins, each resulting from the averaged values of $10 \mathrm{msec}$. LORETA was then applied to this new function considering two time ranges: one from $180 \mathrm{msec}$ to $270 \mathrm{msec}$ (the common range of $\mathrm{N} 200$ elicitation for all groups), the other from $270 \mathrm{msec}$ to 460 msec (the common range of P300 elicitation for all groups). The difference in cortical estimated activation were performed comparing the pure target stimuli effect between patients and controls in the three previously-described groups.

\section{Statistical analysis}

Normality of data was checked using the Kolmogorov Smirnov test. The $t$-test for independent groups was used for comparing latencies in the group as a whole (patients and controls).

The statistic used in LORETA analysis was a Student's t-test on log-normalised data. Correction for multiple comparisons was performed using the randomisation approach ${ }^{27}$ with 5000 randomisations.

The significance level was set at $p<0.05$. Latencies analysis were performed using the Statistica 12.0 software package, while source analysis including regression analysis were performed using the LORETA software package.

\section{Ethical issues}

The local institutional ethics committee approved the study (n. 3842AO16). All experiments were conducted with the informed and overt consent of each participant or caregiver, in accordance with the Code of Ethics of the World Medical Association (Declaration of Helsinki) and the standards established by the local Institutional Review Board.

\section{Results}

All subjects (patients and controls) correctly identified all the target stimuli.

\section{Latency analysis}

Comparing patients and controls in the study population as a whole, the N100, N200 and P300 latencies were significantly longer in patients than in controls $(128.8 \pm 19$ msec and $97.2 \pm 16$, respectively, for $\mathrm{N} 100, \mathrm{p}=0.003$; $239.6 \pm 28 \mathrm{msec}$ and $201.5 \pm 20$, respectively, for N200, $\mathrm{p}=0.0001 ; 353.1 \pm 47$ and $299.5 \pm 21$, respectively, for $\mathrm{P} 300, \mathrm{p}=0.0002)$.

The N200-N100 interval did not differ significantly in patients and in controls $(107.3 \pm 31.6 \mathrm{msec}$ and $103.7 \pm 19.9$, respectively; $\mathrm{p}=0.6)($ Fig 1$)$.

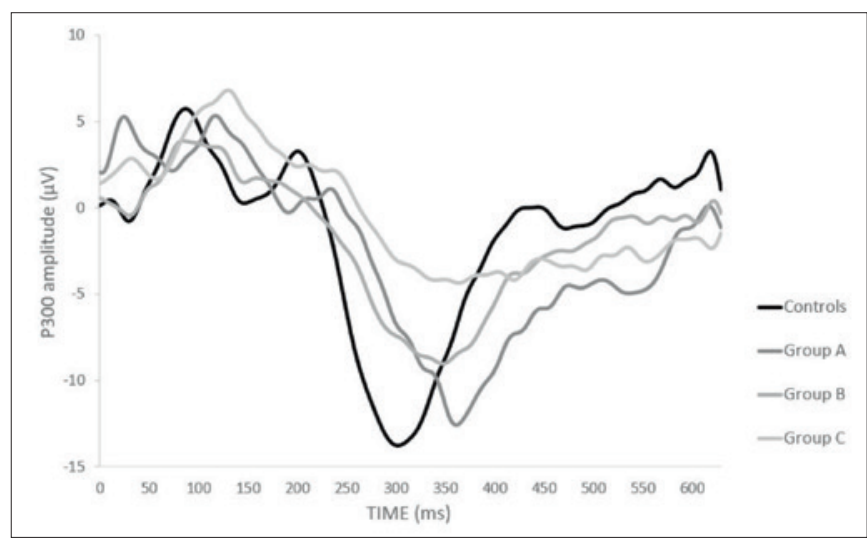

Figure 1. Grand average of target stimuli recorded in $\mathrm{Cz}$ in controls (black line) and patients (grey lines, from darker to lighter) in groups $A, B$ and $C$.

\section{Cortical source analysis}

This analysis was performed as explained in the Methods. In group A (Fig. 2), no significant difference was found between patients and controls in the cortical areas, either for N200 (180-270 ms time window) or for P300 (270-460 time window). In group B (Fig. 3), there was greater activation in frontal areas for both N200 and P300 wave in controls, but the difference was not significant, whereas in group C (Fig. 4) this difference reached statistical significance ( $\mathrm{p}<0.05)$. More precisely, in the N200 time window, controls exhibited a higher activation in frontal areas (BA 8,9 and10) and in the cingulate cortex (BA 24, 32 and 33); and in the P300 time window, we found a significantly

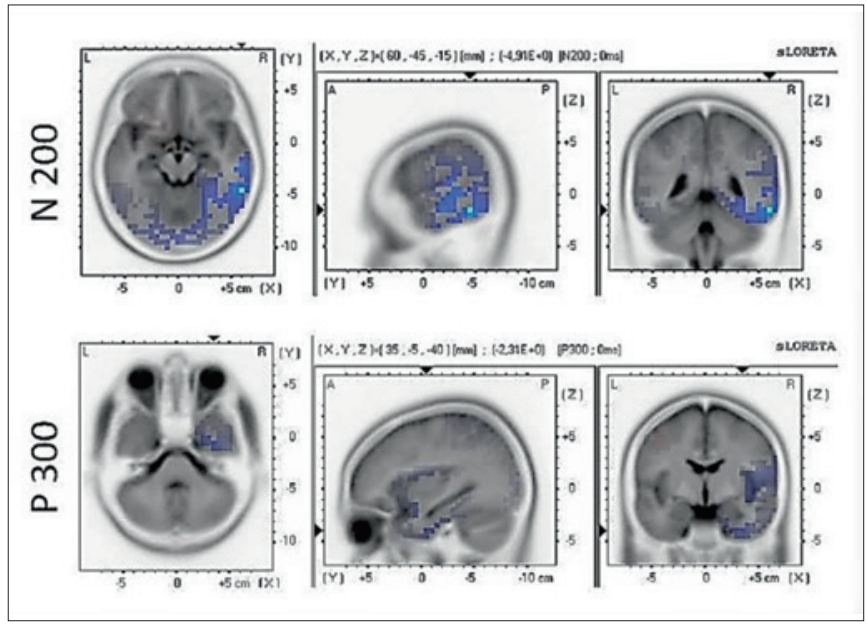

Figure 2. LORETA probabilistic map in cortical difference of activation between patients and controls, in group A. Red colours represent a greater activation in control group, more evident from dark red to yellow. On the contrary, blue colours represent greater activation in the patient group, more evident from dark to light. No significant difference in activation was found in either N200 (above) or in P300 (bottom). 


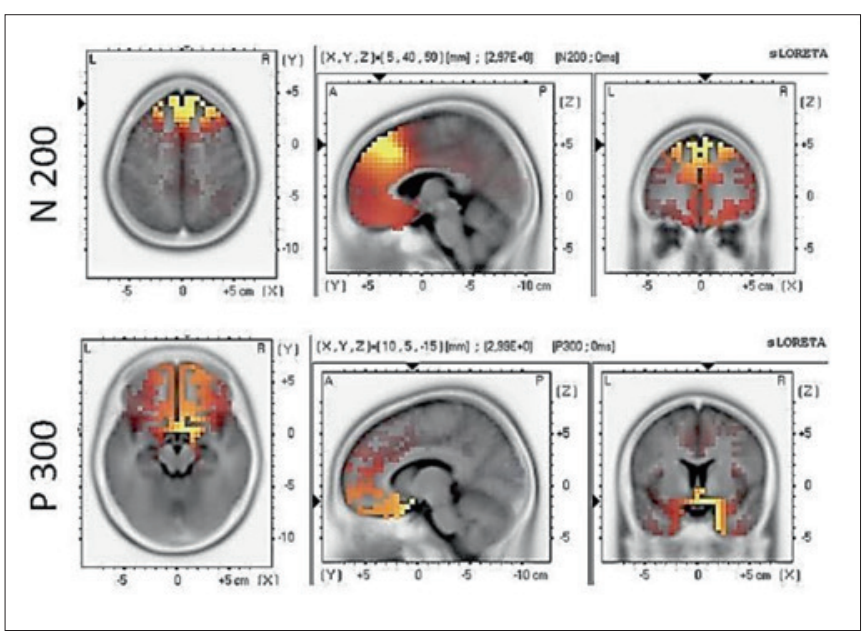

Figure 3. LORETA probabilistic map in cortical difference of activation between patients and controls, in group B. Red colours represent a greater activation in control group, more evident from dark red to yellow. On the contrary, blue colours represent greater activation in the patient group, more evident from dark to light. A greater activation was found in controls, but this difference was not statistically significant in either N200 (above) or in P300 (bottom).

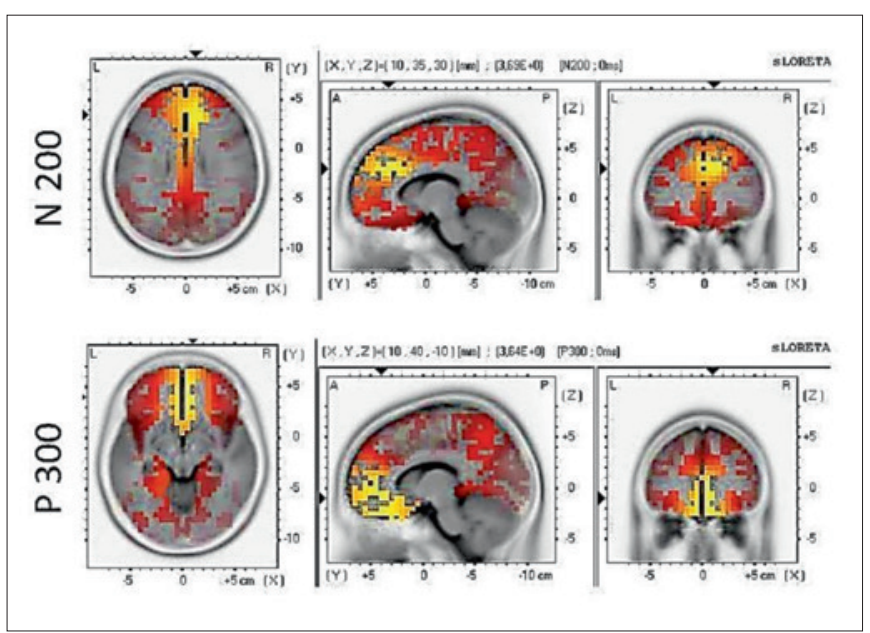

Figure 4. LORETA probabilistic map in cortical difference of activation between patients and controls, in group $\mathrm{C}$. Red colours represent a greater activation in control group, more evident from dark red to yellow. On the contrary, blue colours represent greater activation in the patient group, more evident from dark to light. A greater activation in control group was found (yellow) in the frontal areas and cingulate cortex: this difference was statistically significant in both N200 (above) and P300 (bottom). higher activation again in frontal areas (BA 10,11, and 25) and in cingulate cortex (BA 32). In the patient group, the amount of cortical activation was found to be significantly directly correlated with duration of implant use and significantly correlated inversely with age at implant, for both N200 and P300 waves, as shown in Table III.

\section{Discussion}

The latency analysis showed a significant increase in the $\mathrm{N} 100, \mathrm{~N} 200$ and P300 peaks in patients compared to controls (Fig. 1), while the P300-N100 and the N200-N100 inter-peak latencies did not differ significantly between patients and controls. This means that the difference in N200 and P300 latencies found between patients and controls is due mainly to the N100 latency lag (of about 25-30 msec) in the patient group, a finding previously reported by Ghiselli et al. ${ }^{20}$. Using LORETA on magnetoencephalographic data, Larson ${ }^{28}$ found that the cortical generators of N100, elicited by the oddball paradigm, were located in the Heschl's gyrus, where previous studies identified the tonotopic map of the human auditory cortex (for an exhaustive review, see Saenz ${ }^{29}$ ). There can be no this tonotopic cortical map without the auditory sensory modality, and thus a prelingually deaf patient needs to "create" a new cortical network to analyse acoustic input. Furthermore, the absence of auditory experience compromises both the primary field and more extensively the higher-order areas ${ }^{30}$. It may be that such a network cannot achieve the same performance as a perfect tonotopic cortex.

From a point of view of cortical activation, LORETA analysis disclosed a very clear difference when comparing a group of patients (group C) who had only been using CI for a very short period of time (less than one year) and had suffered long-term neural deprivation, with an age-matched control group. A statistically higher amount of activation in the frontal areas and cingulate cortex was apparent in the controls in comparison with patients, for both the N200 and the P300 waves. Conversely, when comparing an early-implanted patient group that had had long-term CI use (group A) with an age-matched control group, no significant differences emerged between patients and controls for

Table III. Linear correlation coefficient (r) and corresponding significance between amount of cortical activation and, respectively, duration of $\mathrm{Cl}$ use and age at first time of $\mathrm{Cl}$ fitting.

\begin{tabular}{lcc} 
& N200 & P300 \\
Duration of $\mathrm{Cl}$ use & $r=0.78(p<0.01)$ & $r=0.76(p<0.01)$ \\
Age at first time of $\mathrm{Cl}$ fitting & $r=-0.71(\mathrm{p}<0.01)$ & $r=-0.68(\mathrm{p}<0.01)$ \\
\hline
\end{tabular}


either N200 or P300 (Fig. 2). It is well known that longterm implant use and early CI fitting are associated with good audiological performance ${ }^{6}$, but it is noteworthy that these features seem to be associated with a normalisation from neurophysiological standpoint also.

These findings depict two extreme conditions: late implant and short time of CI use, versus early implant and long CI use. An intermediate condition is represented by the patient belonging to group $\mathrm{B}$, which had been using CI for more than one year. In this case a slight, but not statistically significant, tendency for higher activation in controls than in patients was found (Fig. 3).

These results were congruous with the LORETA monovariate regression analysis performed in the patient group, with age of implant and duration of CI use as covariates: the amount of cortical activation was significantly correlated with duration of implant use and significantly correlated inversely with age at implant, for both N200 and P300 waves. It is very important to stress that our results do not imply cognitive impairment due to prelingual deafness: CI provides a new sensory modality in this type of patients, and their neuronal plasticity restores - or rather creates - a functional network which involves the areas implicated in sensory and cognitive modalities. Thus, in other words, CI gives these cortical areas access to a new (for deaf patients) sensory modality. The duration of CI use is clearly crucial: our data suggest that even in case of late-implant, prolonged CI use restores the auditory network. Unfortunately, LORETA software cannot perform multivariate regression analysis, so the pure effect of the duration of CI use and age of implant could not be determined.

The main limitations of the present study are: (i) small sample size; (ii) lack of a group of early-implanted patients with a short period of CI use; (iii) unfeasibility of a cortical source analysis of the N100 wave and limited number of channels. With regards to (i), further patient recruitment is in progress to increase the size of groups A and B to better investigate the relationship between CI age and CI period of use needed for a good performance. The chance to study early-implanted patients with a short use of their CI coincides with the feasibility of administering a P300 paradigm to very young children. The number of EEG channels ${ }^{20}$ does not allow for high spatial resolution. However, our results showed strong significance with regards to our specific question. Therefore, various examples of the use of 19 channels in the ERPs cortical source analysis are available in the scientific literature ${ }^{31-33}$.

\section{References}

National Institute for Health and Clinical Excellence (NICE). 2009. NICE technology appraisal guidance 166: Cochlear implants for chil- dren and adults with severe to profound deafness. Available from: www.nice.org.uk/TA166 (2009; accessed 23 march 2018).

2 May-Mederake B. Early intervention and assessment of speech and language development in young children with cochlear implants. Int J Pediatr Otorhinolaryngol 2012;76:939-46. https://doi.org/10.1016/j. ijporl.2012.02.051

3 Niparko JK, Tobey EA, Thal DJ, et al. Spoken language development in children following cochlear implantation. JAMA 2010;303: 1498506. https://doi.org/10.1001/jama.2010.451

4 Gordon KA, Tanaka S, Wong DDE, et al. Multiple effects of childhood deafness on cortical activity in children receiving bilateral cochlear implants simultaneously. Clin Neurophysiol 2011;122:823-33. https://doi.org/10.1016/j.clinph.2010.10.037

5 Kral A, O'Donoghue GM. Profound deafness in childhood. N Engl J Med 2010;363:1438-50. https://doi.org/10.1056/NEJMra0911225

6 Sharma A, Dorman MF, Spahr AJ. A sensitive period for the development of the central auditory system in children with cochlear implants: implications for age of implantation. Ear Hear 2002;23:532-9. https://doi.org/10.1097/01.AUD.0000042223.62381.01

7 Gordon KA, Wong DDE, Papsin BC. Bilateral input protects the cortex from unilaterally-driven reorganization in children who are deaf. Brain 2013;136(Pt 5):1609-25. https://doi.org/10.1093/brain/awt052

8 Sharma A, Dorman MF, Kral A. The influence of a sensitive period on central auditory development in children with unilateral and bilateral cochlear implants. Hear Res 2005;203:134-43. https://doi. org/10.1016/j.heares.2004.12.010

9 Dumas AR, Schwalje AT, Franco-Vidal V, et al. Cochlear implantation in far-advanced otosclerosis: hearing results and complications. Acta Otorhinolaryngol Ital 2018;38:445-52. https://doi.org/10.14639/0392100X-1442

10 Kral A, Kronenberger WG, Pisoni DB, et al. Neurocognitive factors in sensory restoration of early deafness: a connectome model. Lancet Neurol 2016;15:610-21. https://doi.org/10.1016/S14744422(16)00034-X

11 Kral A, Yusuf PA, Land R. Higher-order auditory areas in congenital deafness: Top-down interactions and corticocortical decoupling. Hear Res 2017;343:50-63. https://doi.org/10.1016/j.heares.2016.08.017

12 Majdani O, Rau TS, Götz F, et al. Artifacts caused by cochlear implants with non-removable magnets in 3T MRI: phantom and cadaveric studies. Eur Arch Otorhinolaryngol 2009;266:1885-90. https:// doi.org/10.1007/s00405-009-0994-8

13 Crane BT, Gottschalk B, Kraut M, et. Magnetic resonance imaging at $1.5 \mathrm{~T}$ after cochlear implantation. Otol Neurotol 2010;31:1215-20. https://doi.org/10.1097/MAO.0b013e3181ec1d61

14 Polich J. Updating P300: an integrative theory of P3a and P3b. Clin Neurophysiol 2007;118:2128-48. https://doi.org/10.1016/j. clinph.2007.04.019

15 Jordan K, Schmidt A, Plotz K, et al. Auditory event-related potentials in post- and prelingually deaf cochlear implant recipients. Am J Otol 1997;18(6Suppl): S116-17

16 Henkin Y, Kileny PR, Hildesheimer M, et al. Phonetic processing in children with cochlear implants: an auditory event-related potentials study. Ear Hear 2008;29:239-49. https://doi.org/10.1097/ aud.0b013e3181645304

17 Reis ACM, Frizzo AC, Isaac Mde L, et al. P300 in Individuals with sensorineural hearing loss. Braz J Otorhinolaryngol 2015;81:126-32. https://doi.org/10.1016/j.bjorl.2014.10.001

18 Beynon AJ, Snik AF, van den Broek P. Evaluation of cochlear implant benefit with auditory cortical evoked potentials. Int J Audiol 2002; 41:429-35

19 Mulert C, Pogarell O, Juckel G, et al. The neural basis of the P300 potential. Focus on the time-course of the underlying cortical genera- 
tors. Eur Arch Psychiatry Clin Neurosci 2004;254:190-8. https://doi. org/10.1007/s00406-004-0469-2

20 Ghiselli S, Gheller F, Trevisi P, et al. The impact of age and duration of cochlear implant in a congenital deaf population: an ERP study. J Biomed Sci Eng 2016;9:384-92. https://doi.org/10.4236/ jbise.2016.98033

21 Henkin Y, Kishon-Rabin L, Tatin-Schneider S, et al. Low-resolution electromagnetic tomography (LORETA) in children with cochlear implants: a preliminary report. Int J Audiol 2004;43(Suppl 1):S48S51.

22 Pascual-Marqui R, Michel CM, Lehmann D. Low resolution electromagnetic tomography: a new method for localizing electrical activity in the brain. Int J Psychophysiol 1994;18:49-65. https://doi. org/10.1016/0167-8760(84)90014-x

23 Valdès P, Picton TW, Trujillo N, et al. Constraining EEG-MEG source imaging with statistical neuroanatomy. Neuroimage 1998;4:635. https://doi.org/10.1016/s1053-8119(18)31468-X

24 Pascual-Marqui RD, Esslen M, Kochi K, et al. Functional imaging with low resolution brain electromagnetic tomography (LORETA): a review. Methods Find Exp Clin Pharmacol 2002;24(Suppl C):91-5.

25 Talairach J, Tournoux P. Co-planar stereotaxic atlas of the human brain. Stuttgart: Thieme; 1988.

26 Romero ACL, Reis ACMB, Oliveira ACS, et al. P300: waves identification with and without subtraction of traces. Int Arch Otorhinolaryngol 2017;21:347-50. https://doi.org/10.1055/s-0037-1599096
27 Nichols TE, Holmes AP. Nonparametric permutation tests for functional neuroimaging: a primer with examples. Hum Brain Mapp 2002;15:1-25.

28 Larson E, Maddox RK, Lee AK. Improving spatial localization in MEG inverse imaging by leveraging intersubject anatomical differences. Front Neurosci 2014;8:330. https://doi.org/10.3389/ fnins.2014.00330

29 Saenz M, Langers DR. Tonotopic mapping of human auditory cortex. Hear Res 2014;307:42-52. https://doi.org/10.1016/j. heares.2013.07.016

30 Yusuf PA, Hubka P, Tillein J et al. Induced cortical responses require developmental sensory experience. Brain 2017;140:3153-65. https:// doi.org/10.1093/brain/awx286

31 Saletu M, Anderer P. Event-related-potential low-resolution brain electromagnetic tomography (ERP-LORETA) suggests decreased energetic resources for cognitive processing in narcolepsy. Clin Neurophysiol 2008;119:1782-94. https://doi.org/10.1016/j. clinph.2008.04.297

32 Van Duynslaeger M, Van Overwalle F, Verstraeten E. Electrophysiological time course and brain areas of spontaneous and intentional trait inferences. Soc Cogn Affect Neurosci 2007;2:174-88. https://doi. org/10.1093/scan/nsm016

33 Calabrò RS, Naro A, Manuli A, et al. Pain perception in patients with chronic disorders of consciousness: what can limbic system tell us? Clin Neurophysiol 2017;128:454-62. https://doi.org/10.1016/j. clinph.2016.12.011 